\title{
Agregacja, koagulacja i wytrącanie się asfaltenów ze strumieni procesowych - przegląd literatury
}

\begin{abstract}
W artykule przedstawiono problematykę wytrącania się asfaltenów, mającą znaczenie głównie w przypadku procesów wydobycia, przesyłu i przeróbki ropy naftowej. Omówiono metodyki badania tego zjawiska. Wskazano podstawowe zależności pomiędzy warunkami procesu a właściwościami fizykochemicznymi wytrąconej frakcji asfaltenowej oraz przybliżono hipotetyczne mechanizmy wyjaśniające kinetykę zjawiska koagulacji.
\end{abstract}

Słowa kluczowe: agregacja, koagulacja, asfalteny, precypitacja.

\section{Aggregation, coagulation and precipitation of asphaltenes from process streams - a literature review}

The article presents the problem of precipitation of asphaltenes of importance mainly for processes of extraction, transportation and processing of crude oil. A methodology for the study of this phenomenon is described. The paper points out fundamental relationships between process conditions and the physicochemical properties of the precipitated asphaltene fraction and describes the hypothetical kinetics mechanisms of the flocculation phenomenon.

Key words: aggregation, flocculation, asphaltenes, precipitation.

\section{Wstęp}

Asfalteny to grupa substancji chemicznych występujących pierwotnie w ropie naftowej, a po jej przeróbce - w całości w pozostałości próżniowej i wysokowrzących przetworach naftowych. Charakteryzuje się je na podstawie nierozpuszczalności w węglowodorach n-parafinowych. Pod względem morfologicznym asfalteny są heterocyklicznymi związkami chemicznymi zawierającymi w swojej budowie atomy siarki, tlenu i azotu. Posiadają peryferyjnie przyłączone łańcuchy alifatyczne i charakteryzują się zdolnością do tworzenia agregatów i klastrów. Asfalteny odznaczają się niekorzystną zdolnością do koagulacji, czyli wytrącania się z ropy naftowej i jej przetworów. Na zjawisko koagulacji asfaltenów wpływ ma wiele czynników fizykochemicznych zaburzających równowagę fazową w układzie gaz-ropa-asfalteny. Do głównych czynników należą: temperatura, ciśnienie, obecność ditlenku węgla, zawartość gazów, pH, zawartość metali, skład chemiczny oraz procesy mechaniczne związane $\mathrm{z}$ mieszaniem i przepływem surowca przez rurociągi.
Wytrącenia frakcji asfaltenowej zmieniają skład, a zatem i właściwości reologiczne surowca, a osadzając się na elementach armatury, utrudniają wydobycie i transport ropy naftowej, co w konsekwencji wymusza konieczność praco- i czasochłonnego oczyszczania instalacji [24]. Ropy lekkie, pomimo niskiej procentowej zawartości asfaltenów (w porównaniu do ciężkich), wykazują większe problemy i skłonności do wytrącania frakcji asfaltenowej. Oczywiście problem ten nie dotyczy odmian rop lekkich, w których frakcja asfaltenowa nie występuje wcale. Jest to spowodowane obecnością węglowodorów parafinowych, w których asfalteny wykazują niewielką rozpuszczalność. Dla rop cięższych zjawisko to jest mniej prawdopodobne, ze względu na szereg związków aromatycznych zawartych w ich składzie (stanowiących dobre rozpuszczalniki asfaltenów) [15]. Aktualnie prowadzone badania mają na celu poznanie właściwości asfaltenów w takim stopniu, aby skutecznie zapobiegać niepożądanym wytrąceniom poprzez kontrolę parametrów procesowych bądź 
w oparciu o pozyskane dane, opracowanie taniej i efektywnej technologii deasfaltyzacji. Najczęściej stosowane są symulacje mające na celu zbadanie, $w$ jakich warunkach temperatury i ciśnienia dochodzi do wytrącenia fazy asfaltenowej.
Prowadzi się je z zastosowaniem metod: grawimetrycznych, rozproszenia światła $[25,33]$, akustycznych, filtracyjnych, badania zmiany (spadku) ciśnienia przy przepływie przez kapilarę [10] oraz badania przewodności elektrycznej.

\section{Kinetyka agregacji asfaltenów - podstawy teoretyczne}

Istnieją dwa modele dotyczące wytrącania się frakcji asfaltenowej. Pierwszy zakłada, że asfalteny posiadają zdolność do tworzenia miceli, poprzez adsorpcję na ich powierzchni polarnych cząsteczek żywic. W przypadku środowiska bogatego w węglowodory aromatyczne, utworzone micele są stabilizowane i nie zachodzi zjawisko wytrącenia się osadu. Gdy w układzie pojawią się n-alkany, dochodzi do zaburzenia równowagi między fazą olejową a zdyspergowaną, co może skutkować wytrąceniem asfaltenów z roztworu. Proces ten jest nieodwracalny ze względu na brak możliwości odtworzenia ochronnej warstwy żywicznej [25]. W 2007 roku na podstawie badań ropy naftowej udowodniono, że żywice nie ulegają asocjacji na powierzchni asfaltenowych nanoagregatów. W ten sposób obalone zostało przekonanie, które istniało od lat 70 . XX wieku. Dodatkowo dowiedziono, że wzrost stężenia asfaltenów nie zmienia rozmiarów, a jedynie liczbę występujących w ropie nanoagregatów [32]. Drugi model zakłada, że asfalteny są rozpuszczone i znajdują się w roztworze w fazie ciekłej, a ich wytrącanie zależy od warunków termodynamicznych. Oznacza to, że koagulacja asfaltenów jest zjawiskiem odwracalnym, a dzięki dobremu poznaniu procesu możliwe jest zaplanowanie go w taki sposób, aby całkowicie wykluczyć wytrącanie. Obecnie uważa się, że oba poglądy są poprawne, a asfalteny występują $\mathrm{w}$ roztworach zarówno $\mathrm{w}$ formie rozpuszczonej, jak i w postaci stabilizowanych żywicami koloidów. Badania mają więc na celu ustalenie, w jakich warunkach ciśnienia i temperatury dochodzi do procesu koagulacji asfaltenów, aby zapobiec temu negatywnemu zjawisku.

W 1998 roku opracowano, w oparciu o pomiar dynamiki rozpraszania światła laserowego, zależność pozwalającą stwierdzić, czy agregacja asfaltenów jest kontrolowana dy- fuzyjnie, czy poprzez szybkość przebiegu procesu. Badania pozwalają na wyznaczenie dwóch charakterystycznych parametrów, jakimi są: $t_{d}$ - czas dyfuzji, $t_{R}-$ czas reakcji, które w założeniu nie są zależne od rozmiarów klastra. Kiedy wartość $t_{d}$ jest większa od $t_{R}$, to proces agregacji asfaltenów kontrolowany jest dyfuzyjnie (ang. Diffusion Limited Aggregation, DLA), w sytuacji odwrotnej - przez szybkość (ang. Reaction Limited Aggregation, RLA). W przypadku modelu dyfuzyjnego każda kolizja cząsteczek prowadzi do agregacji, a ich średnia wielkość jest proporcjonalna do czasu agregacji (szybkość agregacji jest stała). Dla modelu kontrolowanego przez szybkość agregacji przyrost ilości wytrąconych asfaltenów w czasie jest funkcją ilości cząsteczek w agregacie. Zgodnie z przedstawioną teorią, gdy tempo wzrostu zmniejsza się, z czasem zauważalny jest model DLA, zaś gdy się zwiększa - RLA [35]. Spektroskopia korelacji fotonów (ang. Photon Correlation Spectroscopy, PCS) potwierdza wspólistnienie obu mechanizmów agregacji limitowanych przez wartość krytycznego stężenia micelizacji (ang. Critical Micelle Concentration, CMC) [34].

W 2014 roku do analizy kinetyki wytrącania się asfaltenów wykorzystano roztwór modelowy i mikroskop optyczny o powiększeniu pozwalającym wykryć cząsteczki o rozmiarach co najmniej $0,5 \mu \mathrm{m}$. Przewiduje się, że agregacja asfaltenów jest kontrolowana przez wydajność występowania kolizji submikronowych cząsteczek, która zależy od współczynnika dyfuzji i wydajności koagulacji uwarunkowanej gęstością asfaltenów oraz typem i siłą oddziaływań międzycząsteczkowych, a tym samym niezależnej od stężenia. Badania wykazały natomiast, że dla tej samej ilości dodanego czynnika precypitującego szybkość agregacji rośnie wraz ze wzrostem stężenia asfalte-

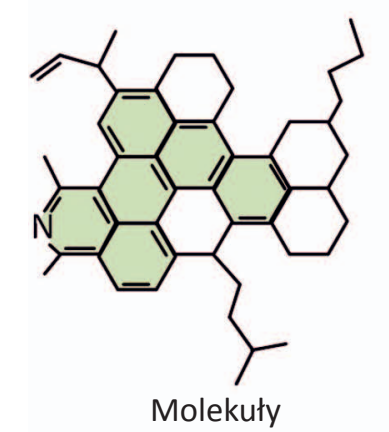

$1,5 \mathrm{~nm}$

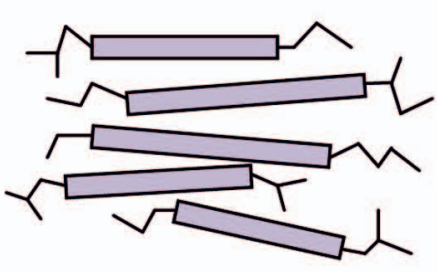

Nanoagregaty $2,0 \mathrm{~nm}$

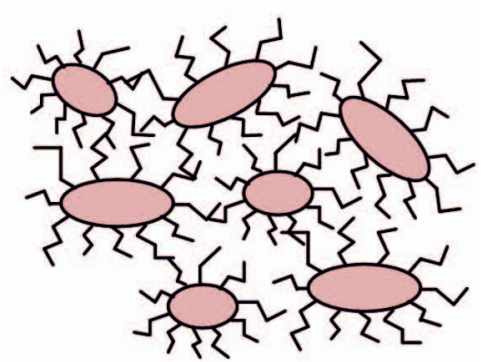

Klastry $5,0 \mathrm{~nm}$
Rys. 1. Zmodyfikowany model Yena budowy asfaltenów [31] nów w rozpuszczalniku (toluenie) w zakresie $0,1 \div 1 \%$, a dla stężeń powyżej $1 \%$ spada. Takie różnice wyjaśnić można poprzez dwa konkurujące efekty. Pierwszym z nich jest wzrost ilości nietrwałych agregatów asfaltenów, których liczba powiększa się wraz ze wzrostem stężenia czynnika 
precypitującego, powodujących zwiększenie częstości kolizji. Drugim efektem jest wzrost parametru rozpuszczalności (miary stopnia oddziaływania pomiędzy asfaltenami), stanowiącego odzwierciedlenie wartości sił międzycząsteczkowych, w wyniku zwiększenia ilości stabilnych agregatów asfaltenów, co prowadzi do spadku wydajności koagulacji. Wyjaśniając wcześniej przedstawione różnice, należy stwierdzić, że agregacja asfaltenów przy stężeniach poniżej 1\% zależy od wzrostu częstotliwości kolizji, natomiast powyżej jest regulowana spadkiem wydajności koagulacji. Dokładna analiza kinetyki koagulacji oraz uwzględnienie występujących w roztworach efektów pozwoliło na modelowanie zachowania się frakcji asfaltenowej z zastosowaniem modelu Smoluchowskiego, który opiera się na dwóch głównych parametrach, jakimi są: częstotliwość kolizji pomiędzy cząsteczkami i ich wydajność [21].

Porównanie wyników modelowania matematycznego, w oparciu o równanie Smoluchowskiego, z analizą kinetyki wytrącania się asfaltenów przy pomocy metody mikroskopowej i z użyciem niskokątowego rozpraszania promieni rentgenowskich (ang. Small-Angle X-ray Scattering, SAXS), wykazało, że może ono być z powodzeniem stosowane. W badaniach wykorzystano asfalteny ropopochodne, a jako rozpuszczalnik: toluen, 1-metylonaftalen oraz ich mieszaninę w proporcji 1:1. Wykazano ponadto, że lepkość oraz parametr rozpuszczalności odgrywają ważną rolę w kontrolowaniu agregacji asfaltenów [20].

W odniesieniu do przedstawionych teorii udowodniono, że krytyczne stężenie micelizacji wzrasta wraz ze spadkiem liczby atomów węgla w łańcuchu alkilowym stosowanego czynnika precypitującego oraz wraz ze wzrostem temperatury. Na wartość CMC wpływ może mieć również wykorzystany w trakcie pomiarów rozpuszczalnik frakcji asfaltenowej, powodując jego wzrost w kolejności pirydyna $<$ nitrobenzen $<$ toluen [14]. Ponadto przy stężeniu miceli poniżej krytycznej wartości $3 \div 4 \mathrm{~g} / \mathrm{L}$ proces agregacji asfaltenów jest kontrolowany dyfuzyjnie, a powyżej tej wartości znaczenia nabierają oddziaływania międzycząsteczkowe [25].

\section{Metody analizy procesu wytrącania asfaltenów}

Kinetykę wytrącania asfaltenów bada się zazwyczaj w komorze z możliwością zaprogramowania stałej wartości ciśnienia, temperatury i objętości (Pressure, Temerature, Volume, PTV). Najczęściej stosowana komora składa się z wysokociśnieniowej celki pomiarowej z wbudowanym, wykonanym z materiału transparentnego, wziernikiem, który umożliwia bieżący monitoring ilości wytrąconej frakcji asfaltenowej. Do obserwacji używa się wysokorozdzielczych kamer, wysokociśnieniowych mikroskopów (ang. High Pressure Microscope, HPM) lub systemów detekcji laserowej (ang. Light Scattering Technique, LST) będących częścią laserowego systemu wykrywania cząstek stałych (ang. Laser Solid Detection System, SDS) i akustycznych technik rezonansowych (ang. Acoustic Resonance Technique, ATR) $[6,8,16]$. Dodatkowo w niektórych komorach zastosowano wysokociśnieniowy filtr membranowy, na którym zbiera się wyizolowana frakcja, a jej procentowa zawartość $\mathrm{w}$ analizowanej próbce może być ustalona grawimetrycznie [7]. Do celki pomiarowej wprowadza się badany surowiec i pozostawia na kilkanaście godzin do ustabilizowania się parametrów początkowych procesu. Następnie umieszcza się czynnik precypitujący, którym może być rozpuszczalnik bądź gaz, np.: ditlenek węgla, i czeka do ponownego ustalenia się równowagi fazowej. Możliwa jest również zmiana parametrów ciśnienia i temperatury bez wprowadzania „substancji” dodatkowych. Procesy zachodzące w celce pomiarowej są na bieżąco monitorowane.
Najczęściej badany i opisywany w kontekście koagulacji asfaltenów jest wpływ temperatury i ciśnienia na to zjawisko. Jednym z parametrów przydatnych $\mathrm{w}$ analizach tego typu jest tzw. dolne i górne ciśnienie precypitacji. Jak wynika $\mathrm{z}$ rysunku 2, przedstawiającego diagram fazowy dla układu ropa-asfalteny-gaz, zjawisko to ma miejsce jedynie pomiędzy wyznaczonymi granicznymi krzywymi.

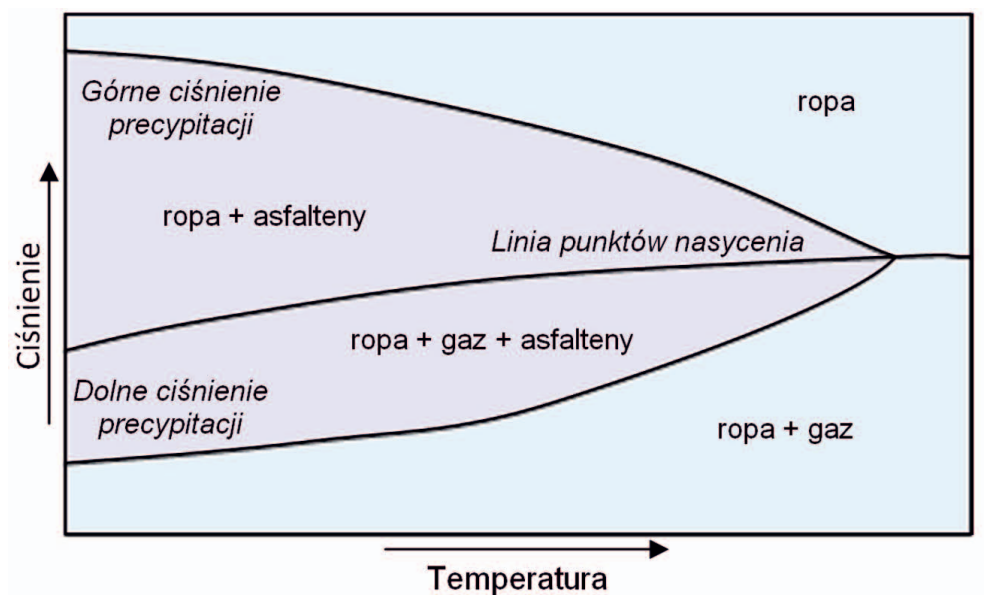

Rys. 2. Przykład typowego diagramu fazowego ropy tworzącej koagulaty asfaltenowe [4]

Badania przeprowadzono dla układu ropa-asfalteny-ditlenek węgla, monitorując proces koagulacji asfaltenów przy zmiennych warunkach ciśnienia. Wykazano, że większość asfaltenów wytrąconych pod ciśnieniem ponad 50 bar na powrót rozpuszcza się w ropie po jego obniżeniu do około 30 bar. 
Procentowa zawartość nierozpuszczalnej frakcji zatrzymanej na filtrze o średnicy porów $5 \mu \mathrm{m}$, zmierzona po dwutygodniowej stabilizacji w temperaturze $27^{\circ} \mathrm{C}$ i przy ciśnieniu 150 bar, wyniosła $5 \%$. Porównując wyniki badań w komorze PTV z metodą klasyczną według ASTM D2007-11, stwierdzono, że z zastosowaniem n-pentanu możliwe jest wydzielenie większej ilości asfaltenów $(6,3 \%)$ posiadających wyższą liczbę atomów węgla w łańcuchu alifatycznym, większą gęstość oraz masę molową [19]. W przypadku ditlenku węgla ilość wytrąconych asfaltenów również rośnie wraz ze wzrostem temperatury i ciśnienia, szczególnie przy ciśnieniach powyżej 100 bar; natomiast maleje, gdy zwiększa się proporcję rozpuszczalnika $\left(\mathrm{CO}_{2}\right)$ do surowca [17].

W roku 2011 wykonano kompleksowe badania zależności wytrąconej frakcji asfaltenowej z zastosowaniem różnych surowców oraz czynników precypitujących w komorze PTV. Analizie poddano lekki i ciężki olej wydobywany ze złóż irańskich w temperaturze 96 i $113^{\circ} \mathrm{C}$ oraz granicach ciśnień od około 2,5 do 350 bar. Czynnikami precypitującymi były: ditlenek węgla, metan i mieszanina metanu i etanu w proporcji 8:2. Badania wykazały, że wraz ze wzrostem temperatury ilość wytrąconych asfaltenów rośnie w przypadku oleju lekkiego, a dla ciężkiego - maleje (w przypadku braku czynnika precypitującego). Zarówno dla metanu, jak i jego mieszaniny z etanem można zaobserwować wzrastający trend, aż do osiągnięcia temperatury wrzenia. Po uzyskaniu tego stanu zwiększenie ilości precypitanta spowoduje spadek liczby wytrąconych asfaltenów, co będzie wiązało się z podziałem lekkich składników ropy w fazie gazowej i ich ponownym rozpuszczeniem się w roztworze. W przypadku próbki oleju lekkiego ilość wytrąceń zmniejsza się wraz ze wzrostem ułamka molowego $\mathrm{CO}_{2}$ (do osiągnięcia temperatury wrzenia), następnie rośnie. Można stwierdzić, że $\mathrm{CO}_{2}$ obniża wpływ ciśnienia i temperatury na precypitację próbki oleju lekkiego [2].

$\mathrm{W}$ innym badaniu również analizowano wpływ ciśnienia $\left(3 \div 8,5\right.$ bar), temperatury $\left(20,8^{\circ} \mathrm{C}\right)$ oraz czynnika precypitującego, jakim jest propan, na wytrącanie się asfaltenów z oleju ciężkiego. Koagulaty zauważalne są w próbce, gdy ciśnienie wzrasta powyżej 8,5 bar, czyli niewiele poniżej prężności par propanu w zadanej temperaturze. W tym badaniu stwierdzono, że świeżo strącone asfalteny mogą ponownie przejść do roztworu, jeśli ciśnienie nasycenia zmniejsza się natychmiast po ich wytrąceniu. Taka sytuacja nie zachodzi jednak w przypadku asfaltenów osadzonych na elementach armatury, które stosunkowo długo pozostają na swoim miejscu [18].

Asfalteny otrzymywać można również jako produkt uboczny w procesie odasfaltowania (ang. Solvent Deasphalting, SDA), w wyniku którego powstaje głównie olej odasfaltowany (ang. Deasphalted Oil, DAO). Ekstrakcja jest najczęściej wykonywana w temperaturze około $200 \div 250^{\circ} \mathrm{C}$ i pod ciśnieniem
$40 \div 130$ bar - w zależności od wykorzystanego rozpuszczalnika, najczęściej pentanu lub heksanu. Badania dowiodły, że zwiększenie liczby atomów węgla w rozpuszczalniku obniża jakość DAO, przy zwiększeniu jego wydajności [29]. Ponadto wydajność ekstrakcji rosła wraz ze wzrostem ciśnienia i temperatury zbliżonej do temperatury krytycznej (pentan: $196,7^{\circ} \mathrm{C}$, heksan: $234,5^{\circ} \mathrm{C}$ ) [3]. Możliwe jest również zastosowanie modyfikatorów, np. acetonu, toluenu, metanolu i octanu etylu. Badania nad połączeniem ich w różnych proporcjach z pentanem wykazały, że wszystkie modyfikatory, z wyłączeniem metanolu, zwiększają wydajność deasfaltyzacji [5]. Badania zależności objętościowego natężenia przepływu rozpuszczalnika w ekstraktorze dowiodły, że precypitacja kontrolowana jest poprzez równowagę międzyfazową, a nie procesy wymiany masy [12].

W 2008 roku Chińska Narodowa Morska Korporacja Naftowa opracowała kombinowany proces dekarbonizacji pozostałości (ang. Residue Decarbonization Combination Process, RDCP) w reaktorze katalitycznym z funkcją deasfaltyzacji rozpuszczalnikowej. W komorze koksującej pozostałości atmosferyczne i próżniowe poddawane są działaniu wysokiej temperatury i niskiego ciśnienia, gdzie cząstki długołańcuchowe ulegają rozkładowi. Następnie produkty są destylowane i usuwa się węglowodory lekkie, podczas gdy frakcja cięższa przesyłana jest do sekcji deasfaltyzacji, gdzie asfalteny oddziela się od wyekstrahowanej pozostałości [27].

Możliwe jest również badanie procesów koagulacji asfaltenów bez dodawania czynnika precypitującego, opierające się wyłącznie na wahaniach ciśnienia i temperatury. Technikę tę wykorzystano w badaniach ropy naftowej przez koncern Chevron do określenia wpływu zmiany ciśnienia na właściwości ropy naftowej. Podczas kontrolowanego spadku ciśnienia w celce pomiarowej poprzez wziernik rejestrowano widmo UV-Vis/NIR w zakresie $800 \div 2500 \mathrm{~nm}$. Badania wykazały, że wytworzone przy wyraźnie zmniejszonym ciśnieniu koagulaty są większe, bardziej „zbite” oraz stabilne, w przeciwieństwie do tych wytworzonych początkowo (zanikających w wyniku ponownego wzrostu ciśnienia). Podejrzewa się, że różnice te mogą mieć związek z adsorpcją większej ilości żywic na powierzchni koagulatów, a tym samym - wzrostem lepkości w przypadku asfaltenów wytrąconych przy większym spadku ciśnienia [13].

Podobne badania wykonano w czterech różnych temperaturach, mieszczących się powyżej krzywej diagramu równowagi fazowej (rysunek 2), dla oleju odgazowanego. Koagulację asfaltenów, po 15-godzinnej stabilizacji, pod wpływem systematycznego izotermicznego obniżania ciśnienia w celce pomiarowej badano z wykorzystaniem detektora NIR i systemu SDS zawierającego laser neonowy do wykrywania zmętnienia roztworu. Pomiary wykonywane były do 
momentu, gdy ilość wydobywających się pęcherzyków gazu nie pozwoliła na dalszy pomiar [11].

Ze względu na wysoki koszt oraz duży nakład pracy, niezbędny do przeprowadzenia serii badań, coraz częściej wprowadza się modele matematyczne oparte np. na ilościowych przedstawieniach cząsteczkowych (ang. Quantitative Molecular Representation, QMR) [23] oraz metodę wykorzystującą stałe równowagi reakcji, stężenie i masę molową asfaltenów [1]. Nowatorską techniką jest zastosowanie dwustanowego modelu Debye'a pozwalającego na wyznaczenie entalpii i entropii agregacji [28].

Równolegle do badań nad zjawiskiem wytrącania się asfaltenów prowadzone są badania nad technikami pozwalającymi zahamować ten proces. Już w latach 70. ubiegłego wieku stwierdzono, że możliwe jest zahamowanie precypitacji asfaltenów na skutek dodania do ropy czynnika peptyzującego, tj. żywicy. Wykazano również, że ważną rolę w osadzaniu się asfaltenów pełnią efekty elektryczne, a konkretniej tzw. ,potencjał strumieniowy” (ang. Streaming potential), generowany przez ruch elektrycznie naładowanych asfaltenów [26]. Tym samym możliwe jest oczyszczanie strumienia procesowego z wytrąconych asfaltenów poprzez elektroosadzanie dodatnio naładowanych cząsteczek asfaltenów na wprowadzonej katodzie. Zahamować precypitację można również, wykorzystując fale ultradźwiękowe [30] oraz stosując środki chemiczne, takie jak np.: epoksydowane alkohole i fenole [14], ciecze jonowe [9] i specjalne mieszaniny niejonowych środków dyspergujących [22].

\section{Podsumowanie}

Istnieje wiele teorii dotyczących wytrącania się asfaltenów ze strumieni procesowych. Najczęstszy jest pogląd o współistnieniu dwóch mechanizmów wytrącania, opartych na współczynniku dyfuzji oraz szybkości reakcji. Niezależnie od mechanizmu, koagulacja asfaltenów zajść może w następstwie wielu czynników, a ilość i wielkość wytrąconych cząsteczek zależeć będzie od rodzaju ropy naftowej, temperatury, ciśnienia, proporcji oraz czynnika precypitującego. Zaproponowane modele opracowane w oparciu o próbki rzeczywiste są wysoce specyficzne ze względu na wyżej wymienione zależności oraz złożoną strukturę frakcji asfaltenowej. W większości przypadków wzrost wydajności precypitacji związany jest ze wzrostem ciśnienia i temperatury oraz spadkiem proporcji surowiec-czynnik precypitujący, jednak nie jest to regułą. Proces wytrącania się asfaltenów zależy ściśle od koperty precypitacji i od tego, czy dana ciecz, o ile jest zastosowana, znajduje się w warunkach nadkrytycznych.

Obecny trend prac badawczych skupia się na opracowywaniu bardziej uniwersalnych modeli matematycznych. Pozwalają one, na podstawie kilku łatwych do zmierzenia parametrów, określić maksymalne wartości ciśnienia i temperatury, w których nie dojdzie do niechcianego wytrącenia się asfaltenów. Ponadto możliwe jest dodanie inhibitorów koagulacji, jednak niewykluczone, że mogą one trwale zmieniać właściwości fizykochemiczne surowca i utrudniać jego dalszą przeróbkę.

Reasumując, należy zauważyć, że konieczne jest prowadzenie dalszych badań nad mechanizmami i sposobami zapobiegania wytrącaniu się asfaltenów w strumieniach procesowych, celem opracowania najbardziej optymalnej i możliwie uniwersalnej technologii.

\section{Podziękowania}

Autorzy pragną złożyć podziękowania prof. dr. hab. inż. Marianowi Kamińskiemu (prof. zw. PG), Kierownikowi Katedry Inżynierii Chemicznej i Procesowej Wydziału Chemicznego Politechniki Gdańskiej, za wiele cennych uwag do wstępnej wersji manuskryptu niniejszej publikacji.

Prosimy cytować jako: Nafta-Gaz 2016, nr 4, s. 293-298, DOI: 10.18668/NG.2016.04.09

Artykuł nadesłano do Redakcji 9.11.2015 r. Zatwierdzono do druku 26.01.2016 r.

Praca finansowana w ramach realizacji projektu badawczego pt. Badania nad otrzymywaniem $i$ właściwościami sorbentów wytwarzanych z asfaltów - finansowanego przez Narodowe Centrum Badań i Rozwoju (Program LIDER, edycja V, nr projektu: LIDER/036/573/L-5/13/NCBR/2014).

\section{Literatura}

[1] Acevedo S., Caetano M., Ranaudo M. A., Jaimes B.: Simulation of asphaltene aggregation and related properties using an equilibrium-based mathematical model. Energy \& Fuels 2011, vol. 25 , s. 3544-3551.
[2] Afshari S., Alizadeh A., Ghazanfari M. H., Kharrat R., Moqadam M. S., Nakhli H.: Monitoring of asphaltene precipitation: Experimental and modeling study. Journal of Petroleum Science and Engineering 2011, vol. 78, s. 384-395. 
[3] Ahn S., Chun J. H., Jeon S. G., Lee J. M., Lee K. B., Mun S. $\mathrm{i}$ in.: Separation of solvent and deasphalted oil for solvent deasphalting process. Fuel Process Technology 2014, vol. 119, s. 204-210.

[4] Akbarzadeh K., Allenson S., Creek J., Hammami A., Jamaluddin A., Kabir S. i in.: Asphaltenes-Problematic but rich in potential. Oilfield Review 2007, nr 2, s. 22-43.

[5] Al-Sabawi M., de Bruijn T., Seth D.: Effect of modifiers in n-pentane on the supercritical extraction of Athabasca bitumen. Fuel Processing Technology 2011, vol. 92, s. 1929-1938.

[6] Anooshe A., Hassanvad M., Shahsavani B.: Study of temperature effect on asphaltene precipitation by visual and quantitative methods. Journal of Petroleum Technology and Alternative Fuels 2012, vol. 3, s. 8-18.

[7] Arciniegas L. M., Babadagli T.: Asphaltene precipitation, flovulation and deposition during solvent injection at elevated temperatures for heavy oil recovery. Fuel 2014, vol. 124, s. 202-211.

[8] Bahadori A., Elkameld A., James L. A., Lohi A., Shafieib A., Zandehboudia S.: Asphaltene precipitation and deposition in oil reservoirs - Technical aspects, experimental and hibrid neural network predictive tools. Chemical Engineering Research and Design 2014, vol. 92, s. 857-875.

[9] Boukherissa M., Mutelet F., Modarressi A., Dicko A., Dafri D., Rogalski M.: Ionic liquids as dispersant of petroleum asphaltenes. Energy \& Fuels 2009, vol. 23, nr 5, s. 2557-2564.

[10] Buckley J. S.: Asphaltene deposition. Energy \& Fuels 2012, vol. 26, s. 4086-4090.

[11] Buenrostro-Gonzalez E., Gil-Villegas A., Lira-Galena C., Wu J.: Asphaltene precipitation in crude oils: Theory and experiments. American Institute of Chemical Engineers Journal 2004, vol. 50, s. $2552-2570$.

[12] Chong K., Monnery W. D., Rose J. L., Syrcek W. Y.: Experimental data for the extraction of Peace Riverbitumen using supercritical ethane. Fuel 2001, 50, s. 1101-1110.

[13] Creek J., Jamaluddin A., Joshi N. B., McFadden J., Mullins O. C.: Asphaltene precipitation from live crude oil. Energy \& Fuels 2001, vol. 15, s. 979-986.

[14] da Silva Ramos A. C., Haraguchi L., Natrispe F. R., Loh W., Mohamed R. S.: Interfacial and colloidal behavior of asphaltenes obtained from Brazilian crude oils. Journal of Petroleum Science Engineering 2001, vol. 32, s. 201-216.

[15] de Boer R. B., Leerlooyer K., Eigner M. R., van Bergen A. R.: Screening of crude oils for asphalt precipitation: theory, practice, and the selection of inhibitors. SPE Production \& Facilities 1995, vol. 10, s. 55-61.

[16] Djema H., Eutamene M., Khodja M., Meniai A. H., Mouloudj N.: Asphaltene precipitation in Algerian oilfields: Experimental investigation and field mitigation. Chemical Engineering Transactions 2014, vol. 39, s. 1663-1668.

[17] Dong Z., Li M., Lin M., Liu G., Wang J.: Experimental study on asphaltene precipitation induced by $\mathrm{CO}_{2}$ flooding. Petroleum Science 2014, vol. 11, s. 174-180.

[18] Gu Y., Luo P.: Characterization of a heavy oil-propane system in the presence or absence of asphaltene precipitation. Fluid Phase Equilibria 2009, 277, s. 1-8.

[19] Gu Y., Wang X.: Characterization of precipitated asphaltenes and deasphalted oils of the medium crude $\mathrm{Oil} \mathrm{CO}_{2}$ and medium crude oil n-pentane systems. Energy \& Fuels 2011, vol. 25, s. 5232-5241.

[20] Haji-Akbari N., Masirisuk P., Hoepfner M. P., Fogler H. S.: A unified model for aggregation of asphaltenes. Energy \& Fuels 2013, vol. 27, s. 2497-2505.

[21] Haji-Akbari N., Teeraphapkul P., Fogler H. S.: Effect of asphaltene concentration on the aggregation and precipitation tendency of asphaltene. Energy \& Fuels 2014, vol. 28, s. 909-919.

[22] Hashmi S. M., Firoozabadi A.: Controlling nonpolar colloidal asphaltene aggregation by electrostatic repulsion. Energy \& Fuels 2012, vol. 26, s. 4438-4444.

[23] Headen T. F., Boek E. S., Skipper N. T.: Evidence for asphaltene nanoaggregation in toluene and haptane from molecular dynamics simulations. Energy \& Fuels 2009, vol. 23, s. 1220-1229.

[24] Jiang T. S., Kawanaka S., Mansoori G. A.: Asphaltene deposition and its role in petroleum production and processing. Arabian Journal for Science and Engineering 1988, vol. 13, s. 17-34.

[25] Khoshandam A., Alamdari A.: Kinetics of asphaltene precipitation in a heptane-toluene mixture. Energy \& Fuels 2010, vol. 24, s. 1917-1924.

[26] Leontaritis K., Mansoori G.: Asphaltene deposition: A survey of field experiences and research approaches. Journal of Petroleum and Science Engineering 1988, vol. 1, nr 3, s. 229-239.

[27] Liang J., Zhang Y.: A new method of processing heavy oil: Residue decarbonization technology (RDCP). $19^{\text {th }}$ World Petroleum Congress. Madryt 2008.

[28] Lisitza N. V., Freed D. E., Sen P. N., Song Y.: Study of asphaltene nanoaggregation by nuclear magnetic resonance. Energy \& Fuels 2009, vol. 23, nr 3, s. 1189-1193.

[29] Modarresi H., Sattarin M., Talachi H., Teymori M.: Solvent deasphalting of vacuum residue in a bench-scale unit. Petroleum and Coal 2006, vol. 48, nr 3, s. 14-19.

[30] Mousavi S. M., Najafi I., Ghazanfari M. H., Amani M.: Comparison of ultrasonic wave radiation effects on asphaltene aggregation in toluene-pentane mixture between heavy and extra heavy crude oils. Journal of Energy Resources Technology - Transactions of the ASME 2012, vol. 134, s. 1-6.

[31] Mullins O. C.: The modified Yen model. Energy \& Fuels 2010, vol. 24, s. 2179-2207.

[32] Mullins O. C., Betancourt S. S., Cribbs M. E., Dbost F. X., Creek J. L., Ballard Andrews A. i in.: The colloidal structure of crude oil and the structure of oil reservoirs. Energy \& Fuels 2007, vol. 21, s. 2785-2794.

[33] Warnecki M.: Doskonalenie technik badań warunków flokulacji asfaltenów metoda prześwietlania ropy strumieniem światta podczerwonego. Nafta-Gaz 2011, nr 7, s. 454-462.

[34] Yudin I. K., Nikolaenko G. L., Gorodetskii E. E., Kosoy V. I., Melikyan V. R., Markhashov E. L. i in.: Mechanisms of asphaltene aggregation in toluene-heptanes mixtures. Journal of Petroleum Science and Engineering 1998, vol. 20, s. 297-301.

[35] Yudin I. K., Nikolaenko G. L., Gorodetskii E. E., Markhashov E. L., Agayan V. A., Anisimov M. A. i in.: Crossover kinetics of asphaltene aggregation in hydrocarbon solutions. Physica A 1998, vol. 251, s. 235-244.

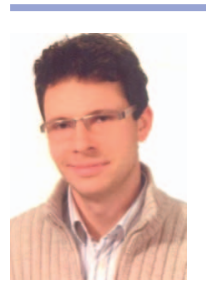

Dr inż. Grzegorz BOCZKAJ

Adiunkt w Katedrze Inżynierii Chemicznej i Procesowej

Wydział Chemiczny Politechnika Gdańska

ul. Gabriela Narutowicza 11/12

80-233 Gdańsk

E-mail grzegorz.boczkaj@gmail.com 